\title{
PARETO OPTIMAL REDISTRIBUTION AND PRIVATE CHARITY
}

\author{
Peter G. WARR* \\ Australian National Universily, Canberra, A.C.T., Australia
}

Received May 1981, revised version received January 1982

\begin{abstract}
When private charity exists and is motivated by utility interdependence a non-Pareto optimal outcome, the 'free-rider' problem, typically arises. Nevertheless, incremental fiscal redistribution cannot achieve a Paretian welfare improvement so long as private charity continues at positive levels. Donors respond to incremental fiscal redistributions by reducing their voluntary contributions by exactly a dollar for every dollar transferred in this way. No net transfer is achieved unless incremental fiscal redistribution is pursued to the point where private contributions have been driven to zero. Alternatively, a net transfer may be achieved by fiscal measures which affect donors' marginal incentives to donate.
\end{abstract}

\section{Introduction}

When either the consumption or the utility of one individual enters the utility function of another, a transfer of income can sometimes benefit both. Under such conditions of utility interdependence, private charity may or may not exist, but if it does, then a 'free-rider' problem will typically arise. Provided the number of donors is at least two, when individual donors have exhausted the gains independently available to them from donating voluntarily, additional gains could potentially be achieved from further incremental transfers. ${ }^{1}$ Each donor benefits from such additional transfers provided other donors are constrained to do likewise. In this analysis, such transfers take on the character of a public good. The equilibrium arising under positive private charitable donations is not Pareto optimal, and institutional arrangements causing additional transfers to be made can potentially result in a Paretian welfare improvement.

\footnotetext{
*The paper has benefited from the comments of two referees and an editor, Geoffrey Brennan, Yew-Kwang Ng and, in particular, J.J. Pincus and Brian D. Wright. The author is responsible for the views presented and any errors.

'See, for example, Hochman and Rodgers (1969), Goldfarb (1970), Musgrave (1970) and Von Furstenberg and Meuller (1971). Of these, Goldfarb provides the most rigorous proof. A more rigorous proof is given in Arrow (1979). For an anticipation of this argument, see Friedman (1962, p. 191). As Goldfarb (1970) points out, this argument has much in common with the Marglin-Sen 'isolation paradox' argument that has been used in discussion of the appropriate discount rate for benefit-cost analysis. On this, see Warr and Wright (1981).
} 
This line of argument has been used, in a series of papers commencing with Hochman and Rodgers (1969), to justify incremental fiscal redistribution of income on grounds of Paretian efficiency. ${ }^{2}$ These discussions have typically had two characteristics in common: (a) the form of fiscal redistribution under consideration is lump sum from the point of view of the individual 'donor'; the amount of tax taken from him and transferred to recipients may depend on his income, which is given from the outside the model, but it does not depend. upon his actual behaviour; and (b) while it is acknowledged that private charity may occur, given the underlying assumption of utility interdependence, the fiscal redistribution under discussion is treated as being additional to this. ${ }^{3}$ What is not to be found in these discussions is a consideration of the possibility that donors will respond to fiscal redistribution by adjusting the levels of their voluntary donations.

The present note draws on the model of utility interdependence developed in the earlier analyses to analyze the effects of redistribution through taxation when these fiscal redistributions coexist with private charitable donations. It is shown that an equilibrium characterized by positive voluntary charitable donations motivated by utility interdependence is not Pareto optimal, but that small incremental fiscal redistributions of the type described in the literature cannot achieve a Paretian welfare improvement. When the response of donors is taken into account these measures result in no net redistribution at all; far from being additional to voluntary redistribution, these taxes merely substitute public fiscal redistribution for private charity, dollar for dollar. ${ }^{4}$ Such measures, which leave donors' marginal incentives to donate unaffected, can begin to induce Paretian welfare improvements only when pursued to the point where private charity has been eliminated. We then show that an alternative fiscal mechanism may in principle be devised which, by altering donor incentives at the margin, is capable of achieving a Paretian welfare improvement in the presence of private charity.

\section{Private charity}

Imagine an economy with two 'rich' individuals and one 'poor', in which

${ }^{2}$ See also Meyer and Shipley (1970), Musgrave (1970), Goldfarb (1970), Hochman and Rodgers (1970, 1973a, 1973b, 1974), Von Furstenberg and Meuller (1971), Mishan (1972), Brennan and Walsh (1973), and Orr (1976).

${ }^{3}$ Thus, for example, Hochman and Rodgers (1969) write: "And when we turn to the N-person case, we assume that the possibility of voluntary redistribution through private charity has been exhausted, thus focusing attention on the incremental redistribution activities carried out under public auspices' (p. 543). Similarly, Goldfarb (1970) writes: 'Our approach in this comment is to show that, once voluntary redistribution is exhausted, the incremental redistribution activities left over in fact be Pareto optimal' (p. 994).

${ }^{4}$ The substitution of public for private redistribution has also been an issue in discussions of the social security system. See Barro (1974). 
the consumption of the poor individual enters the utility functions of the rich. To keep the discussion simple, we shall suppose that the two rich individuals are each unconcerned about the consumption the other. The two rich individuals will be denoted 1 and 2 and the poor individual is denoted 3 . The rich have the utility functions $U^{k}=U^{k}\left(c^{k}, c^{3}\right), k=1,2$, where $c^{i}, i=1,2,3$, denotes the consumption of individual $i$. Individual 3 has the utility function $U^{3}=U^{3}\left(c^{3}\right)$. The functions $U^{i}, i=1,2,3$, are each concave, twice differentiable and strictly increasing in all arguments; so there is no 'envy' or 'malice'. Each individual receives a lump-sum income, denoted $y^{i}$, which is determined outside the present model. For our purposes it is to be considered given for each individual.

We now assume that individuals 1 and 2 make non-negative voluntary donations, denoted $v^{1}$ and $v^{2}$, respectively, to individual 3 . The consumption of each of the three individuals is given by

$$
c^{i}=y^{i}-v^{i}, \quad i=1,2,
$$

and

$$
c^{3}=y^{3}+v^{1}+v^{2}
$$

The charitable donations of individuals 1 and 2 are each set separately so as to maximize that individual's utility, treating the other's donations as given. This implies the Kuhn-Tucker conditions $v^{i}\left(U_{i}^{i}-U_{3}^{i}\right)=0$ and $U_{i}^{i}-U_{3}^{i} \geqq 0$, where $i=1,2$, and, as usual, $U_{j}^{i} \equiv \partial U^{i} / \partial c^{j}$. We shall now consider the welfare properties of the Nash equilibrium that this defines.

Consider first the solution where both donors make positive charitable contributions $\left(v^{i}>0, i=1,2\right)$, implying

$$
U_{i}^{i}\left(c^{i}, c^{3}\right)=U_{3}^{i}\left(c^{i}, c^{3}\right), \quad i=1,2
$$

Each donor sets the level of his contributions such that from his point of view the marginal utilities attaching to his own and the recipient's consumption are equated. ${ }^{5}$ To see that this equilibrium is not Pareto optimal, imagine individuals 1 and 2 to have initially chosen their optimal charitable donations, as given by (3), and now consider a binding contract between them committing each to increase his total contributions to individual 3 by one unit. The effect of this on individual $i$ 's welfare is given by

$$
\mathrm{d} U^{i}=-U_{i}^{i}+2 U_{3}^{i},
$$

\footnotetext{
${ }^{5}$ Private charity may occur for reasons other than utility interdependence as, for example, when the levels of donations themselves, as distinct from the resulting consumption of recipients, enter donors' utility functions. This form of charity is ignored in the Pareto optimal redistribution literature and in the present note because when charity takes this form alone the initial equilibrium is already Pareto optimal.
} 
which from (3) is necessarily positive. Both donors benefit from this combination of transfers and so, obviously, does the recipient. Alternatively, we can derive the necessary conditions for Pareto optimality. This can be done by maximizing, say, individual 3's utility subject to the constraints $U^{1}\left(c^{1}, c^{3}\right) \geqq \bar{U}^{1}, U^{2}\left(c^{2}, c^{3}\right) \geqq \bar{U}^{2}$ and $c^{1}+c^{2}+c^{3}=y^{1}+y^{2}+y^{3}$, where $\bar{U}^{1}$ and $\bar{U}^{2}$ are positive constants. This gives the condition

$$
U_{3}^{1} / U_{1}^{1}+U_{3}^{2} / U_{2}^{2}=1
$$

a result which is familiar from public goods theory and which is clearly inconsistent with (3).

Now consider the solution where charitable contributions are zero for both donors. We now have $U_{i}^{i} \geqq U_{3}^{i}, i=1,2$. If we again contemplate the above hypothetical contract, the sign of (4) is now indeterminate. Donor $i$ may gain, lose, or be unaffected by participation in such a contract. But since the marginal utilities involved have no behavioural manifestation there is no way for the external observer to distinguish one case from the other. There is consequently no way of establishing in practice whether an income transfer constitutes a Paretian welfare improvement or not unless potential donors can be induced to reveal their preferences through some other means. It is therefore convenient for discussion of the 'free-rider' problem to assume charitable donations to be positive, in which case the non-Pareto optimality of the initial solution is unambiguous. But the implications of voluntary charity for the effectiveness of fiscal redistribution have not been appreciated.

\section{Fiscal redistribution}

We now suppose both donors to be making positive private charitable contributions initially and consider the impact of the type of incremental fiscal redistribution discussed in the literature. A lump-sum tax is applied to individuals 1 and 2 with the proceeds being distributed to individual 3 . It is important to realize that such a tax is unlike the hypothetical social contract described above in that it does not directly determine the total transfer to individual 3, only a marginal fiscal transfer, leaving the private voluntary component of the total transfer to the choice of individuals 1 and 2. For reasons that will quickly become clear, we assume for now that the magnitude of this tax, $T$, is smaller then the levels of the private charitable donations $v^{1}$ and $v^{2}$ obtaining in the absence of the tax, and for the purpose of the present discussion, we consider the effects of a small change in this tax.

Incorporating this tax into (1) and (2) and differentiating with respect to $T$ we obtain:

$$
\mathrm{d} c^{i} / \mathrm{d} T=-\mathrm{d} v^{i} / \mathrm{d} T-1, \quad i=1,2
$$


and

$$
\mathrm{d} c^{3} / \mathrm{d} T=\mathrm{d} v^{1} / \mathrm{d} T+\mathrm{d} v^{2} / \mathrm{d} T+2
$$

Similarly, since the two equations given by (3) must hold before and after the tax is varied, it is legitimate to differentiate them with respect to $T$, obtaining:

$$
J_{1} \mathrm{~d} c^{1} / \mathrm{d} T+J_{3} \mathrm{dc} c^{3} / \mathrm{d} T=0
$$

and

$$
K_{2} \mathrm{~d} c^{2} / \mathrm{d} T+K_{3} \mathrm{~d} c^{3} / \mathrm{d} T=0
$$

where $J_{i} \equiv\left(U_{3 i}^{1}-U_{1 i}^{1}\right)$ and $K_{i} \equiv\left(U_{3 i}^{2}-U_{2 i}^{2}\right)$. Now, substituting from eqs. (6) and (7) into (8) and (9) we obtain two equations in $\mathrm{d} v^{1} / \mathrm{d} T$ and $\mathrm{d} v^{2} / \mathrm{d} T$ with solution $\mathrm{d} v^{1} / \mathrm{d} T=\mathrm{d} v^{2} / \mathrm{d} T=-1$.

Now consider the effects of progressively raising the tax on each donor by one dollar. The net redistribution that results can be discussed in three phases. The first phase, analyzed above, where both individuals' charitable donations are positive, corresponds to zero net transfer. Taxing donors in this way simply induces each to contract his voluntary donations by exactly the amount of the tax, so as to re-establish his marginal equilibrium condition given by (3). The recipient is made no better off by this and neither is either donor. Nothing changes except that public fiscal redistribution substitutes on a 'one-for-one' basis for private charity. As the magnitude of the tax is increased this process continues until the private charitable donations of at least one donor are forced to zero. The third phase, where all charitable donations have vanished, corresponds to a two dollar net transfer to individual 3. The intermediate phase, where one individual's donations are positive and the other's are zero, corresponds to a net transfer of a fraction of one dollar. Suppose individual 2's donations reach zero first (implying that individual 2's donations were initially smaller). Taxing individual 2 by a further dollar causes a one dollar transfer from him to individual 3 . Individual 1 offscts the effect of the tax on himself by reducing his own donations by one dollar, but then reduces them further, by a fraction of a dollar given by $\left(U_{33}^{1}-U_{13}^{1}\right) /\left(U_{11}^{1}+2 U_{13}^{1}\right)$, on noticing that individual 3 has been made a dollar better off by the transfer from 2 .

\section{A marginal fiscal incentive to donate}

Although incremental fiscal redistribution does not achieve a Paretian welfare improvement in the presence of private charity, alternative fiscal solutions to this problem do exist. We shall show this by considering a tax on donors' consumption and an accompanying subsidy on donations, with the latter set for each donor such that the combined tax and subsidy raise zero 
net revenue. This combined tax and subsidy is convenient for our purposes in that it avoids complications arising from the income effects induced by the net revenue implications of either a tax or subsidy alone. For each donor, the subsidy on donations is set so as to return exactly the amount of revenue raised by the tax on his consumption, but from his point of view these tax and subsidy rates are set exogenously and must be treated as given. Let the rate of tax on each donor be $t$ and the rates of subsidy for donors 1 and 2 be $s^{1}$ and $s^{2}$, respectively. Taking donor 1 as our example, his problem is: $\max U^{1}\left(c^{1}, c^{2}\right)$ with respect to $v^{1}$ and $c^{1}$ subject to the constraints $\left(y^{1}-v^{1}\right)$ $(1-t)+s^{1} v^{1}-c^{1} \geqq 0, c^{3}=y^{3}+v^{1}+v^{2}$ and $v^{1} \geqq 0$, treating $y^{1}, y^{3}, v^{2}, t$ and $s^{1}$ as given. This implies the Kuhn-Tucker conditions $U_{3}^{1}-U_{1}^{1}\left(1-t-s^{1}\right) \geqq 0$ and $v^{1}\left(U_{3}^{1}-U_{1}^{1}\left(1-t-s^{1}\right)\right)=0$. For $v^{1}>0$ this implies

$$
U_{3}^{1}=U_{1}^{1}\left(1-t-s^{1}\right) \text {. }
$$

Now consider a change in the rate of the tax accompanied by appropriate increases in the rates of subsidy so as to eliminate for each donor the budgetary effects of the tax. We shall evaluate the effects of a change in this tax cum subsidy at the point where it is first introduced. That is, starting from the equilibrium under positive private charity discussed above we consider the effects of introducing a small tax and accompanying subsidy. First, since we require zero net revenue effect for donor $i,\left(y^{i}-v^{i}\right) \mathrm{d} t=v^{i} \mathrm{~d} s^{i}$. The rate at which $s^{i}$ must be adjusted is thus $\mathrm{d} s^{i} / \mathrm{d} t=\left(y^{i}-v^{i}\right) / v^{i}$. The rate of change of donor is consumption is $\mathrm{d} c^{i} / \mathrm{d} t=v^{i}-y^{i}+v^{i} \mathrm{~d} s^{i} / \mathrm{d} t--\mathrm{d} v^{i} / \mathrm{d} t$ which then reduces to $\mathrm{d} c^{i} / \mathrm{d} t=-\mathrm{d} v^{i} / \mathrm{d} t$. Thus, since $\mathrm{d} c^{3}=\mathrm{d} v^{1}+\mathrm{d} v^{2}, \sum_{i=1}^{3} \mathrm{~d} c^{i} / \mathrm{d} t=0$. Differentiating the two equations given by (10) with respect to $t$ now gives three equations in the variables $\mathrm{d} c^{i} / \mathrm{d} t, i=1,2,3$. Solving for $d \mathrm{c}^{1} / \mathrm{d} t$ we obtain

$$
\mathrm{d} v^{1} / \mathrm{d} t=U_{1}^{1}\left(y^{1} / v^{1}\right)\left(K_{2}-K_{3}\right) / D+U_{2}^{2}\left(y^{2} / v^{2}\right) J_{3} / D
$$

where $J_{i}$ and $K_{i}$ are essentially as before and $D \equiv J_{1}\left(K_{2}-K_{3}\right)-J_{3} K_{2}$.

This expression can be interpreted in two parts. First, suppose the tax and accompanying subsidy was applied to individual 1 alone, with no tax or subsidy applied to individual. 2. Proceeding as above, we find that $\mathrm{d} v^{1} / \mathrm{d} t$ is then given by the first term of the right-hand side of (11). This term represents the substitution effect on individual 1's donations of a tax and subsidy applied solely to him. Under weak additional restrictions on individual utility functions this term is always positive. ${ }^{6}$ Similarly, applying

\footnotetext{
${ }^{6} \mathrm{~A}$ sufficient restriction is that cross-partial second derivatives are non-negative $\left(U_{i j}^{i} \geqq 0, i \neq j\right)$. This is consistent with, but not directly implied by, concavity. Strict concavity already implies $U_{i i}^{i}<0$ and together these imply $J_{1}, K_{2}<0$ and $J_{3}, K_{3}>0$. Conditions $J_{3}-J_{1}>0$ and $K_{3}-K_{2}>0$ are already implied by diminishing marginal rate of substitution of donor preference maps (convexity of indifference curves from below). For example, writing $z^{1} \equiv U_{3}^{1} / U_{1}^{1}$ for individual 1's marginal rate of substitution $\mathrm{d} z^{1} / \mathrm{d} c^{3}=J_{1}-J_{3}$.
} 
the tax and accompanying subsidy solely to individual 2 , we find that $\mathrm{d} y^{1} / \mathrm{d} t$ is given by the second term of (11), which thus represents individual 1's adjustment of his contributions in response to a tax and subsidy induced expansion of individual 2's donations. Under the same assumptions on individual utility functions, this term is negative. Eq. (11) is therefore the sum of two terms of opposite sign. This indeterminacy of sign does not apply to the effect of the tax and subsidy scheme on the consumption of the recipient. This is given by $\mathrm{d} c^{3} / \mathrm{d} t=\mathrm{d} v^{1} / \mathrm{d} t+\mathrm{d} v^{2} / \mathrm{d} t$ which, from our earlier assumptions, proves to be positive. The second term of (11) and the corresponding term for donor 2 drop out of the expression. Under our assumptions, either both donors' charitable contributions rise in response to the tax-subsidy, or one's donations fall and the other's rise by a greater amount. Total contributions must rise. The typical case must be the one in which both donors' contributions rise.

Now consider the welfare effects of the tax and subsidy. From the fact that the recipient's consumption rises, he obviously benefits. For donor 1 we have $\mathrm{d} U^{1} / \mathrm{d} t=U_{1}^{1} \mathrm{~d} c^{1} / \mathrm{d} t+U_{3}^{1} \mathrm{~d} c^{3} / \mathrm{d} t$ which, from (3), becomes $\mathrm{d} U^{1} / \mathrm{d} t=U_{1}^{1}\left(\mathrm{~d} c^{1} / \mathrm{d} t\right.$ $\left.+\mathrm{d} c^{3} / \mathrm{d} t\right)=U_{1}^{1}\left(\mathrm{~d} v^{2} / \mathrm{d} t\right)$. Individual 1 benefits from the tax-subsidy applied to both donors so long as the other donor's contributions to the recipient rise as a result of it, and vice versa. In the typical case, both donors and the recipient benefit. A Pareto optimal solution can be obtained by setting the variables $t, s^{1}$ and $s^{2}$ such that the three equations given by the zero net revenue conditions for each of the two donors and eq. (5) are satisfied.?

${ }^{7} \mathrm{~A}$ Pareto optimum can also be reached by means of a tax and subsidy applied uniformly across donors, with these two variables set such that eq. (5) and a zero aggregate net revenue condition are satisfied. But this solution will not always be one in which both donors gain relative to their initial position; it will not always be Pareto superior to the equilibrium under private charity.

\section{References}

Arrow, Kenneth J., 1979, Optimal and voluntary income distribution, Technical Report No. 288, Institute for Mathematical Studies in the Social Sciences, Stanford University.

Barro, Robert J., 1974, Are guvernulent bonds net weallh?, Jounal of Political Economy 82, 1095-1117

Brennan, H.G. and C. Walsh, 1973, Pareto optimal redistribution reconsidered, Public Finance Quarterly 1, 147-168.

Friedman, Milton, 1962, Capitalism and freedom (University of Chicago Press, Chicago).

Goldfarb, Robert S., 1970, Pareto optimal redistribution: Comment, American Economic Review $50,994-996$.

Hochman, Harold M. and James D. Rodgers, 1969, Pareto optimal redistribution, American Economic Review 59, 542-557.

Hochman, Harold M. and James D. Rodgers, 1970, Pareto optimal redistribution: Reply, American Economic Review 60, 997-1004.

Hochman, Harold M. and James D. Rodgers, 1973a, Brennan and Walsh reconsidered, Public Finance Quarterly 1, 359-371. 
Hochman, Harold M. and James D. Rodgers, 1973b, Utility interdependence and income transfers through charity, in: Kenneth E. Bouling, Martin Pfaff and Anita Pfaff, eds., Transfers in an urbanized economy (Wadsworth, Belmont).

Hochman, Harold M. and James D. Rodgers, 1974, Redistribution and the Pareto criterion, American Economic Review 64, 752-757

Meyer, Paul A. and J.J. Shipley, 1970, Pareto optimal redistribution: Comment, American Economic Review 50, 988-990.

Mishan, E.J., 1972, The futility of Pareto-efficient distributions, American Economic Review 62, 971-976.

Musgrave, Richard A., 1970, Pareto optimal redistribution: Comment, American Economic Review 50, 991-993.

Orr, Larry L., 1976, Income transfers as a public good: An application to AFDC, American Economic Review 66, 359-371.

Von Furstenberg, George M. and Dennis C. Meuller, 1971, The Pareto optimal approach to income redistribution: A fiscal application, American Economic Review 61, 628-637.

Warr, Peter G. and Brian D. Wright, 1981, The isolation paradox and the discount rate for benefit-cost analysis, Quarterly Journal of Economics 95, 129-145. 